\title{
Romana Brovia, Tradizione e ricezione del Petrarca latino in Francia. Rassegna di studi fra due centenari (1904-2004)
}

\section{Paola Cifarelli}

\section{(2) OpenEdition \\ Journals}

\section{Edizione digitale}

URL: http://journals.openedition.org/studifrancesi/27316

DOI: $10.4000 /$ studifrancesi.27316

ISSN: 2421-5856

\section{Editore}

Rosenberg \& Sellier

\section{Edizione cartacea}

Data di pubblicazione: 31 décembre 2006

Paginazione: 584-585

ISSN: 0039-2944

\section{Notizia bibliografica digitale}

Paola Cifarelli, « Romana Brovia, Tradizione e ricezione del Petrarca latino in Francia. Rassegna di studi fra due centenari (1904-2004) », Studi Francesi [Online], 150 (L | III) | 2006, online dal 30 novembre 2015, consultato il 08 novembre 2020. URL : http://journals.openedition.org/studifrancesi/27316 ; DOI : https://doi.org/10.4000/studifrancesi.27316

\section{Questo documento è stato generato automaticamente il 8 novembre 2020}

\section{cc) $($ ) $\ominus$}

Studi Francesi è distribuita con Licenza Creative Commons Attribuzione - Non commerciale - Non opere derivate 4.0 Internazionale. 


\title{
Romana Brovia, Tradizione e ricezione del Petrarca latino in Francia. Rassegna di studi fra due centenari (1904-2004)
}

\author{
Paola Cifarelli
}

\section{NOTIZIA}

ROMANA BROVIA, Tradizione e ricezione del Petrarca latino in Francia. Rassegna di studi fra due centenari (1904-2004), «Lettere Italiane» LVII, n.2, 2005, pp. 287-327.

1 Il nutrito articolo di questa giovane studiosa, che al Petrarca latino e alla diffusione delle sue opere in Francia ha dedicato vari lavori, è molto più di una rassegna bibliografica degli studi pubblicati negli ultimi cent'anni sul Petrarca latino, e particolarmente sulla sua fortuna francese. All'esaustività delle informazioni contenute in questo lavoro si aggiunge una rara capacità di cogliere gli snodi essenziali della storiografia, mettendo in evidenza l'evoluzione del pensiero critico sulla portata culturale della ricezione di Petrarca in Francia.

2 La ricca materia qui recensita viene organizzata in tre sezioni. Nella prima, intitolata Edizioni e traduzioni, sono segnalate le imprese editoriali realizzate o in corso di realizzazione per rendere disponibili le opere latine del sommo poeta, in edizioni critiche affidabili e in traduzione. L'A. si sofferma sul rinnovato interesse per questi testi a partire dagli anni Novanta, sulla spinta degli studi realizzati da F. Simone e dalla sua scuola a Torino, segnalando in particolare le edizioni apparse presso le edizioni Rivages a Parigi e Millon a Grenoble, oltre alle edizioni bilingui progettate da Les Belles Lettres.

3 La seconda sezione (Studi sulla fortuna francese del Petrarca latino) si apre sugli importanti lavori di Pierre de Nolhac e Augustin Renaudet, che segnano l'inizio di un approccio critico nuovo alla materia petrarchesca; del primo, incentrato sull'indagine della ricezione delle opere latine in ambito europeo durante il Tre e Quattrocento, R. Brovia 
sottolinea il ruolo chiave per la promozione di nuove ricerche finalizzate al censimento di codici ed edizioni a stampa; quanto al secondo, è noto che stimolò particolarmente gli studi sulla storia della cultura nell'ambito dei rapporti tra Francia ed Italia. Questi due filoni di ricerca vengono osservati nei loro sviluppi ulteriori, che li vedono coniugarsi dapprima nelle indagini svolte da A. Coville, poi in quelle condotte a partire dal dopoguerra da G. Billanovich ed infine negli studi pubblicati da F. Simone negli anni Cinquanta e dagli studiosi formatisi alla sua scuola nei decenni successivi. In questa ricca panoramica delle ricerche condotte anche da eruditi torinesi, le circostanze della divulgazione europea degli scritti petrarcheschi vengono esaminate nella prospettiva di una minuziosa e preliminare ricostruzione della situazione storico-culturale e di un'attenta lettura dei testi che degli scritti latini del Petrarca subirono la profonda influenza. Gli studi di G. Di Stefano sulle traduzioni di Valerio Massimo, quelli di L. Sozzi su Poggio e Tardif, le ricerche di E. Ornato su Jean de Montreuil e l'Umanesimo parigino, insieme agli studi di N. Mann sulla fortuna del De Remediis vengono evocati nel lavoro di R. Brovia per il ruolo avuto nella profonda trasformazione degli schemi storiografici sul Quattrocento francese. Dopo aver seguito la ricezione del Petrarca anche durante il Sei e Settecento, la studiosa segnala, nell'ultima sezione, gli studi sulle opere latine, mettendo in luce la fioritura delle ricerche soprattutto in corrispondenza delle celebrazioni per i centenari. Oltre agli studi più marcatamente letterari, sono citati anche i principali lavori di carattere storico, filologico, filosofico e retorico. Merito di questo lavoro, che renderà un utilissimo servizio agli studiosi, è anche quello di sottolineare alcune piste di ricerca finora poco esplorate, come la diffusione a stampa dei testi petrarcheschi o l'esegesi di singole opere latine. 